УДК $331.1,316.3,316.4$

$10.17213 / 2075-2067-2020-6-28-38$

\title{
СИСТЕМНОЕ УПРАВЛЕНИЕ КОМАНДНОЙ РАБОТОЙ НА ОСНОВЕ ГУМАНИТАРНОГО РАЗВИТИЯ КОНЦЕПЦИИ СОЦИАЛЬНОГО ТЕХНОПАКЕТИРОВАНИЯ
}

\author{
(C) 2020 г. В. П. Бабинцев", М. А. Федотова ${ }^{* *}$, П. В. Полуиин ${ }^{* * *}$
}

"Белгородский государственный национальный исследовательский университет, 2. Белгород, Россия

** Московский авиационный институт (национальный исследовательский университет), г. Москва, Россия

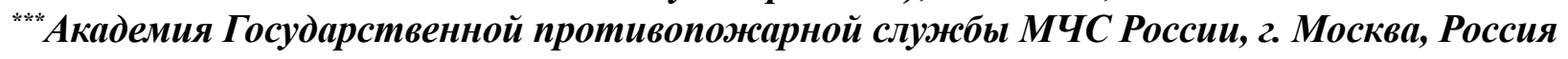

Целями исследования являются: обоснование возможности моделирования управления несколькими (сетью) технопакетами, формирующими макропакет; анализ практических результатов моделирования адаптивного управления/стратегирования технопакетами «управление командной работой» и «проектное управление».

Методологическую базу исследования составляют вопросы, связанные с развитием и практическим использованием в социальном управлении концепџии технопакетирования («технопакетов») (С. Переслегин, Б. Кудрин, К. Перес, Г. Малинеикий, У. Ульрих, М. Джексон, Дюс. Олига и др.).

Результаты исследования. Приводится краткое описание классического варианта конщепџии «технопакетов», предлагается расширение списка основных понятий конщепџии, вводятся новые типь технологий/субпакетов - «оптимизирующая» $и$ «развивающая» технологии, исследуются возможности их применения в сочиальном управлении. Анализируются возможности синтеза инструментов технопакетирования и «мягких» вычислений (МАИ-технология Т. Саати).

Перспективы исследования. Рассматриваются основные проблемы управления технопакетами, предлагаются новые перспективные направления развития концепџии «технопакетов» на основе неклассических логик.

Ключевые слова: технопакет; система/сеть технопакетов (макропакет); субпакеmbl/mехнологии технопакета; оптимизирующая и развивающая технологии технопакета; МАИ-технология «мягких» вычислений; SMC-framework проектного управления; адаптивное управление/стратегирование макропакетом.

\section{SYSTEM MANAGEMENT OF TEAM WORK BASED ON THE HUMANITARIAN DEVELOPMENT OF THE CONCEPT OF SOCIAL TECHNOLOGY PACKAGING}

\author{
(C) 2020 V. P. Babintsev", M. A. Fedotova ${ }^{* *}$, P. V. Polushin ${ }^{* * *}$ \\ *Belgorod State University, Belgorod, Russia \\ ${ }^{* *}$ Moscow Aviation Institute (National Research University), Moscow, Russia \\ ${ }^{* * *}$ Academy of the State fire service of the EMERCOM of Russia, Moscow, Russia
}

Objectives of the study are: the feasibility of modeling manage multiple (network) technoratti forming the macro package; analysis of simulation results of adaptive control/strategizing technorattanu the «management team» and «project management». 
The methodological basis of the research is issues related to the development and practical use of the concept of technopacketing («technopackets») in social management (S. Pereslegin, B. Kudrin, K. Peres, G. Malinetsky, W. Ulrich, M. Jackson, J. Oligo, etc.).

Research result. A brief description of the classical version of the concept of «technopolitan», proposed expanding the list of key concepts concept introduces new types of technologies/ subpackages — «optimizing» and "developing» technology, explores the possibilities of their application in social management. The possibilities of synthesis of technopackaging tools and «soft» computing (MAI-technology of T. Saati) are analyzed.

Prospects of the study. The main problems of managing technopackages are considered, and new promising directions for the development of the concept of «technopackages» based on nonclassical logics are proposed.

Key words: technopath; system/network technopathic (the macro package); subpackages/ technology tehnomarket; optimizing and developing technology tehnomarket; MAI-technology soft computing; SMC-project management framework; adaptive management/strategizing a macro package.

Введение. Концепция «технопакетов», основы которой были заложены С. Переслегиным [10], наряду с теорией техноценоза Б. Кудрина [4], технолого-инвестиционных циклов К. Перес [9] и нелинейной социодинамики Г. Малинецкого [7] как естественного развития теории социального управления позволяет связывать стратегию социального развития с генезисом и развитием технологий различных видов - ускоряющих/физических, управляющих и коммуникационных [10]. Технологическим пакетом (ТП) в концепции «технопакетов» C. Переслегина является «генетически и структурно функционально связанная совокупность различных технологий системного характера, реализующая одну из социально значимых потребностей» [10]. Как продукт техногенной цивилизации, концепция «технопакетов» является чисто технологическим инструментом управления со всеми присущими ему недостатками, прежде всего, отсутствием субъектности управления. Эту проблему авторы статьи предлагают решать с помощью использования концепции соционавигации как наиболее общей социальной практики в рамках социогуманитарной цивилизации $[5,15]$, в которой процесс технопакетирования осуществляется на базе эмансипационного системного подхода (Ульрих У., Джексон М., Олига Дж.) [6].

Как было показано в более ранних работах авторов статьи $[15,20]$, дифференциация концепции технопакетов (элементов/ технологической среды) позволяет повысить эффективность управления социальными процессами (вследствие закона кибернетики У. Эшби об адекватности управляющей и управляемой систем). Продолжая тему развития технологизации социального управления и опираясь на уже полученные результаты, авторы стремились более детально раскрыть содержание ранее предложенных инноваций и показать их управленческую эффективность на конкретных примерах. Речь, прежде всего, пойдет о двух ранее предложенных авторами понятиях ТП - «оптимизирующая» и «развивающая» технологии/субпакеты [15], a также о расширении понятия «базовая» технология как технология формирования объекта ТП (для ТП «управление командной работой», такой технологией является технология формирования и диагностики команд).

Методология и методы. Основная гипотеза статьи состоит в том, что дифференциация понятий концепции «технопакетов», их расширение и развитие позволяют повысить эффективность управления как отдельными ТП, так и сетью ТП (макропакетами). Трансформация объекта ТП, лежащего в основе базовой технологии ТП, позволяет концептуально развивать весь ТП. Подобная трансформация объекта достигается путем использования неклассических логик. Наиболее подходящими методами моделирования управления ТП и макро-ТП являются 
методы «мягких» вычислений, например, МАИ/МАС-технологии Т. Саати, позволяющие осуществлять адаптивное управление/ стратегирование ТП/макро-ТП в режиме бриколажа «здесь и сейчас».

В новой редакции «базовая» технология (БТ) может быть представлена как технология, формирующая объект ТП и делающая пакет «физически» возможным, создающая субстанцианальность/«вещественность» ТП. Развитие такой БТ в конечном счете привело к формированию ТП. Именно работа с объектом БТ задает формирование и дальнейшее концептуальное развитие ТП. Трансформация объекта ТП осуществляется с использованием математического аппарата неклассических логик.

В этом свете понятие «продуктовые» технологии/субпакеты ТП формируют предметную часть/части объекта ТП, представляясь в виде физических/гуманитарных (управляющих) технологий, обеспечивающих управление, производство, обмен и реализацию/ утилизацию конечных товаров услуг, социоформ проектов, в т.ч. самих команд как «продуктов» социального проектирования и конструирования на базе концепции соционавигации как социальной практики в условиях неравновесности [15].

«Замыкающая» технология/субпакет (ЗмТ) - технология, связывающая набор технологий (базовой и продуктовых) в единую целесообразную систему, как правило, по экономическому критерию. В нашем примере ЗмТ - технология управления образовательно-карьерной и деловой (аутсорсинг) траекторией (ОКТ) команд. Наличие аутсорсинга и «биржи» команд приводит к целесообразной, экономически выгодной трансформации социальной среды, позволяющей эффективно развивать технопакет (в этом случае решение является собственной функцией среды).

«Закрывающие» технологии/субпакеты (3Т) - технологии, позволяющие реализовывать потребности на принципиально ином качественном уровне, например, с меньшими затратами ресурсов, более высокой социально-экономической и технологической эффективностью, а также нежелательными эффектами и последствиями. В нашем примере 3Т технология управления командной работой на основе искусственного интеллекта (AI).
«Оптимизирующие» технологии/субпакеты (ОТ) характеризуют «внутреннюю» (внутрипакетную), прежде всего, организационно-экономическую эффективность ТП, позволяя рационализировать/оптимизировать параметры используемых «базовой» и «продуктовых» технологий (объекта и предмета ТП). В этом случае объект БТ узнается «как тот же самый» [17].

«Развивающие» технологии/субпакеты (РТ), в свою очередь, характеризуют «внешнюю» социальную и технико-технологическую эффективность ТП, что связано, как правило, с развитием «замыкающей» или «закрывающей» технологии ТП, в последнем случае, как правило, через разрешение парадокса.

Наибольший эффект от работы с оптимизирующими и развивающими технологиями, как будет показано ниже, возникает в случае работы с сетью ТП - макропакетом. «Оптимизирующими» и «развивающими» технологиями/субпакетами могут быть как физические, так и гуманитарные (управляющие) технологии. Общая схема структуры технопакета представлена на рисунке 1.

Наглядным примером такого управления является деятельность компании SpaceX И. Маска, связанная с ТП1 «космос» (проект ракеты многоразового использования Falcon9 - минимизация затрат на космические запуски) и ТП2 «интернет» (проект Starlink - минимизация затрат на создание дешевого и скоростного низкоорбитального интернета). Подготовка ракеты Falcon9 к повторному запуску сейчас занимает несколько месяцев, после отладки процесса (поточного метода) на нее потребуется меньше месяца. Многоразовость первой ступени Falcon9 это оптимизация БТ - запуска космического аппарата в ТП «космос», но это лишь первая часть сетевого управления технопакетами. SpaceX планирует развернуть спутниковую группировку в количестве 11943 спутников, что позволит снизить раздачу интернета с орбиты в 36 тыс. км (задержка радиосигнала от 0,5 сек) до 340 км, при этом пинг станет, как у обычных провайдеров. В этом случае SpaceX становится спутниковым интернетмонополистом. Сравнение выручки от реализации обоих ТП приведено на рисунке 2 (выделено светло-серым - планируемая выручка SpaceX от пусков Falcon9, черным - 
от мирового рынка низкоорбитального интернета). Многоразовость первой ступени Falcon9 обеспечивает дешевую замену спутников (жизненный ресурс каждого около 6 лет) для эффективного поддержания группировки в космосе. Этот пример еще раз показывает основную проблему современного управления - отсутствие эффективной системы управления. Научиться управлять сетью ТП и макропакетами - значит научиться управлять эффективностью социально-экономических процессов в целом. Используя две оптимизирующие технологии в каждом из ТП, SpaceX достигает огромного синергетического эффекта для макропакета из двух ТП в целом. При этом нельзя забывать военную составляющую этого макропакета. «Закрывающей» технологией для ТП1 является технология орбитального запуска (вне земной гравитации).

Научные результаты и дискуссия. Поиск наиболее эффективных оптимизирующих и развивающих технологий в предлага- емой авторами методике управления ТП осуществляется с помощью технологий «мягких» вычислений, в нашем случае - МАИтехнологии Т. Саати в схеме адаптивного планирования/управления (стратегирования) проблемными ситуациями (ПС) [11]. Схема использования представлена на рисунке 3.

Обобщенный сценарий для «прямого» прогона на рисунке 2 (левая иерархия) может включать в себя несколько параметров (frame), характеризующих, например, альтернативные варианты минимизации затрат на запуски космических аппаратов, начиная от физических/технико-технологических характеристик таких аппаратов и заканчивая схемой вывода аппарата/спутника на орбиту и его приземления, подготовку и организацию зпуска (экваториальные запуски и т.д.). В практическом исследовании сетевого управления технопакетами «управление командной работой» и «проектное управление» обобщенный сценарий включал в себя параметры состояния BSC-метрик (сбалансированная система показателей): финансовые,

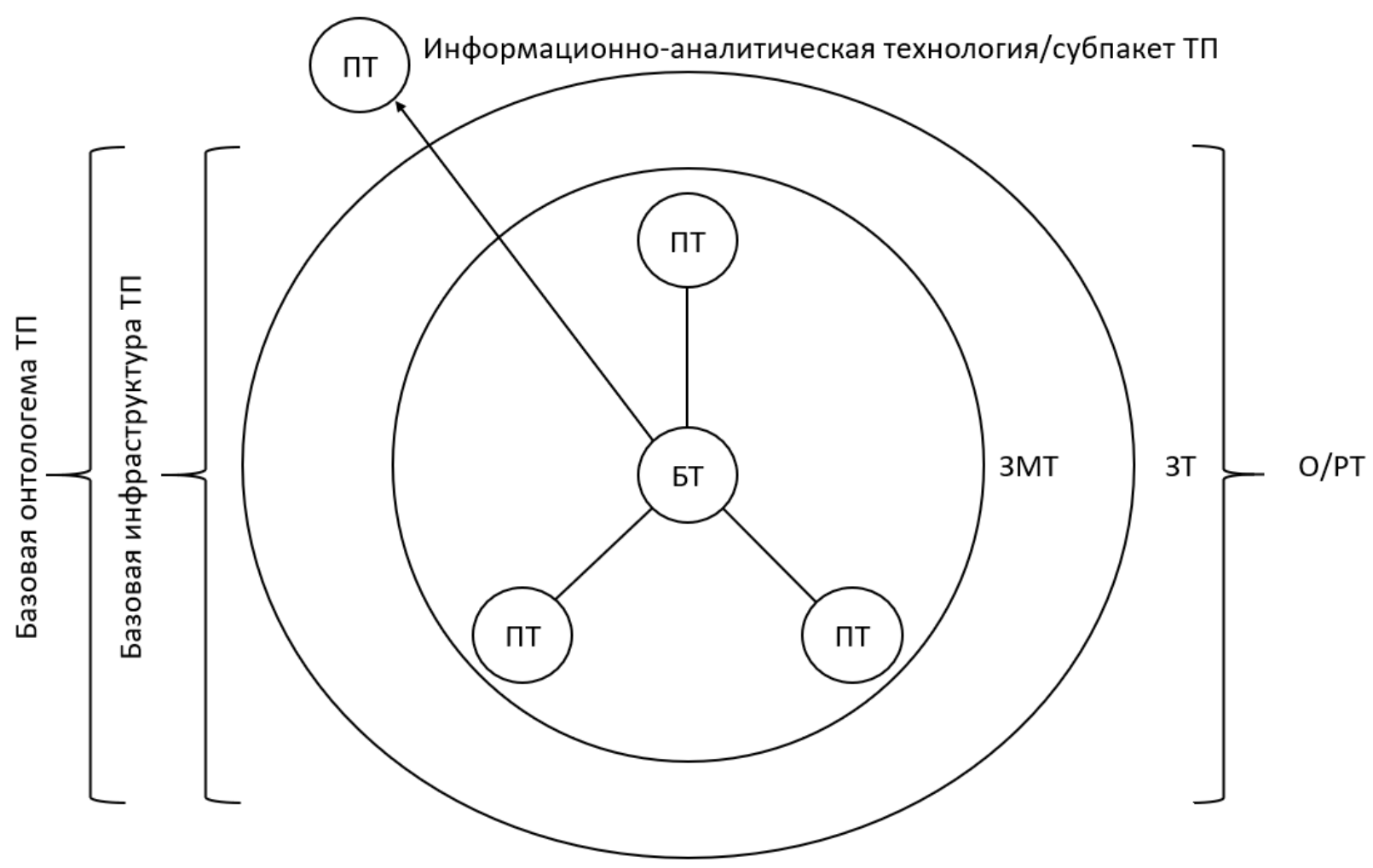

Рис. 1. Общая схема структуры ТП

(БТ - «базовая» технология, ПТ - «продуктовые» технологии, ЗМТ - «замыкающая» технология, ЗТ - «закрывающая» технология, $\mathrm{O} / \mathrm{PT}$ - «оптимизирующие/развивающие» технологии) 
маркетинговые, процессные и персональные. Следует отметить, что альтернативы, имеющие различное содержание (физическая или гуманитарная/управленческая) могут дополнять друг друга, создавая синергетический эффект. В рассмотренном выше примере используется эффект двух оптимизирующих технологий/субпакетов - минимизация затрат на запуски позволяет увеличить число последних, которая позволяет нарастить количество интернет-спутников на орбите, что, в свою очередь, позволяет снизить их орбиту, уменьшая время интернет-сигнала. В этой ситуации глобальный интернет-проект Starlink становится вне конкуренции.

Предлагаемая в статье технология управления технопакетами имеет другую, более сложную, конфигурацию, представленную на рисунке 3. Эта технология управления макропакетом основана на двух развивающих технологиях - развитие базовой технологии (объекта БТ — команды) ТП1 «уп- равление командной работой» и производственной технологией (ПТ) ТП2 «проектное управление». Данная технология управления макропакетом предназначена для разрешения ключевого противоречия управления проектами: ориентация команды только на проект (развитие проекта) и одновременная необходимость развития самой команды. В существующих технологиях проектного управления, а также формах и форматах командной работы данное противоречие не может быть разрешено. Однако, используя понятие «развивающая» технология при управлении ТП1 и ТП2, противоречие можно разрешить в виде совмещения/суперпозиции процессов проектирования и обучения (метод дробления и восстановления на новой основе ТРИЗ) [17] с медиатором в виде единого креативного поля (ЕКП) команды [8]. В этом случае получается новое решение в виде специального формата управленческого проектирования (SMC-framework), основанного на широко

\section{Reaching for the Stars}

Space $X$ projects that soaring revenue from its planned satellite-internet business will dwarf its launch revenue.

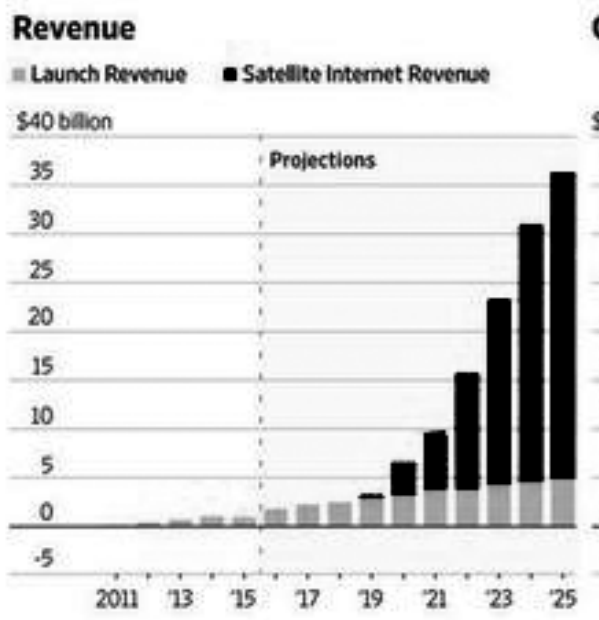

\section{Operating income}

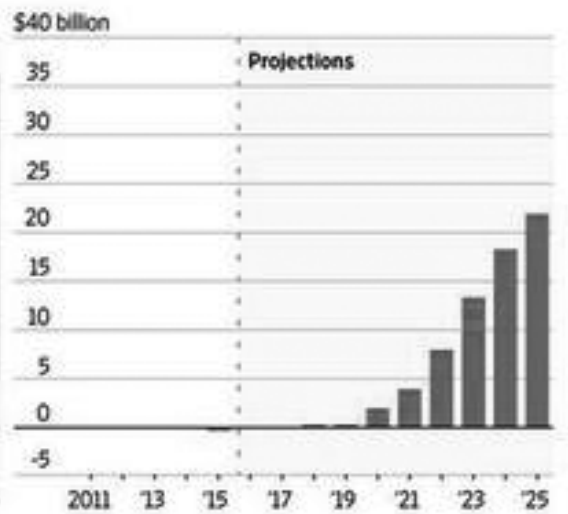

On the Launchpad

The company forecasts a dramatic increase in launches in coming years. Accidents in 2015 and 2016 caused planned launches to be delayed.

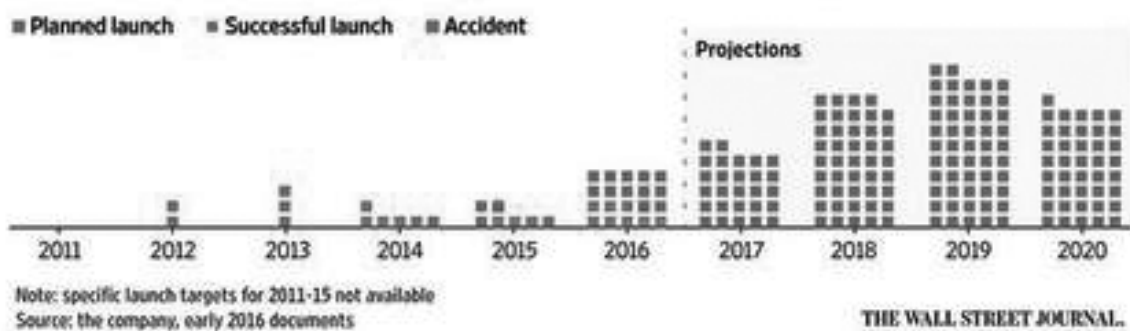

Рис. 2. Сравнение выручки от реализации ТП «космос» и ТП «интернет» компании SpaceX 
используемой технологии SCRUM с добавлением еще одного исключительно важного принципа - «команда важнее проекта». Для того чтобы получить SMC-framework, необходимо изменить объект в БТ ТП1 «управление командной работой» путем использования моделей неклассических логик: объектом БТ ТП1 является команда (напомним, что БТ заключается в процессе формирования и/или диагностики такой команды). В настоящее время любая команда состоит из нескольких участников - людей (HR), т.е. в конечном счете объект-команда состоит из HR. Если развить объект (a - одно) до схемы (AI) R, мы получим противоположный объект (не a другое, как правило, противоположное), далее мы можем перейти к схеме (a \& не а и одно, и другое) - (H\&AI) R, потом к схеме не (а \& не a) — ни одно, ни другое, а третье: (H') R, где H' - измененное состояние сознания (ИСС) [2, 14, 22] участников/команды, которая реализуется в среде ЕКП (Н' является временным, сформированным с использованием специальных технологий состоянием). Далее переходим к схеме не (a \& не a) $\left(\left(\mathrm{H} \rightarrow \mathrm{H}^{\prime}\right)\right.$ \& AI) R и т.д. Разумеется, изменение объектов БТ в ТП1 в настоящее время реально возможно лишь в схеме $\left(\mathrm{H} \rightarrow \mathrm{H}^{\prime}\right) \mathrm{R}$, которая реализована в ТФ командах [19].

Системное моделирование управления командной работой включает в себя, кроме МАИ-иерархий выбора оптимальных для каждого этапа управления альтернатив (статический/квазидинамический аспект — параметр времени в этих моделях присутствует неявно/ дискретно), оптимальные/рационализирующие модели корректировки этих альтернатив в процессе их реализации (динамический аспект - параметр времени входит в эти модели в явном виде). Например, если вы выбрали оптимальной альтернативой (стратегией) объекта БТ ТП1 схему $\left(\mathrm{H} \rightarrow \mathrm{H}^{\prime}\right) \mathrm{R}$, реализующуюся в среде ЕКП ТФ-команды, то архиважно определиться с тактикой использования этой схемы при реализации конкретного управленческого проекта (наиболее интересна тактика поведения команды в ситуациях когнитивного «тупика»/блокады) [3]. В этом случае нужен другой тип моделей, например, когнитивные модели [1], позволяющие учесть динамический аспект процесса управления командами [16]. Дополняя когнитивные модели анализом организации командного мышления [3], можно определить индивидуальные паттерны мышления и поведения команд с целью их дальнейшего развития. Как уже было показано в [20], наиболее эффективным инструментом управления командной работой, начиная от ее формирования/диагностики и заканчивая разработкой и продвижением HR-бренда команды и ее образовательно-карьерной траекторией (ОКТ), являются «гибридные» системы моделей (ГСМ), включающие в себя как классические методы, например, статистический и регрессионный анализ, так и неклассические - методы искусственного интеллекта (ИИ). Такая ГСМ должна обеспечивать эффективность решений всего комплекса задач

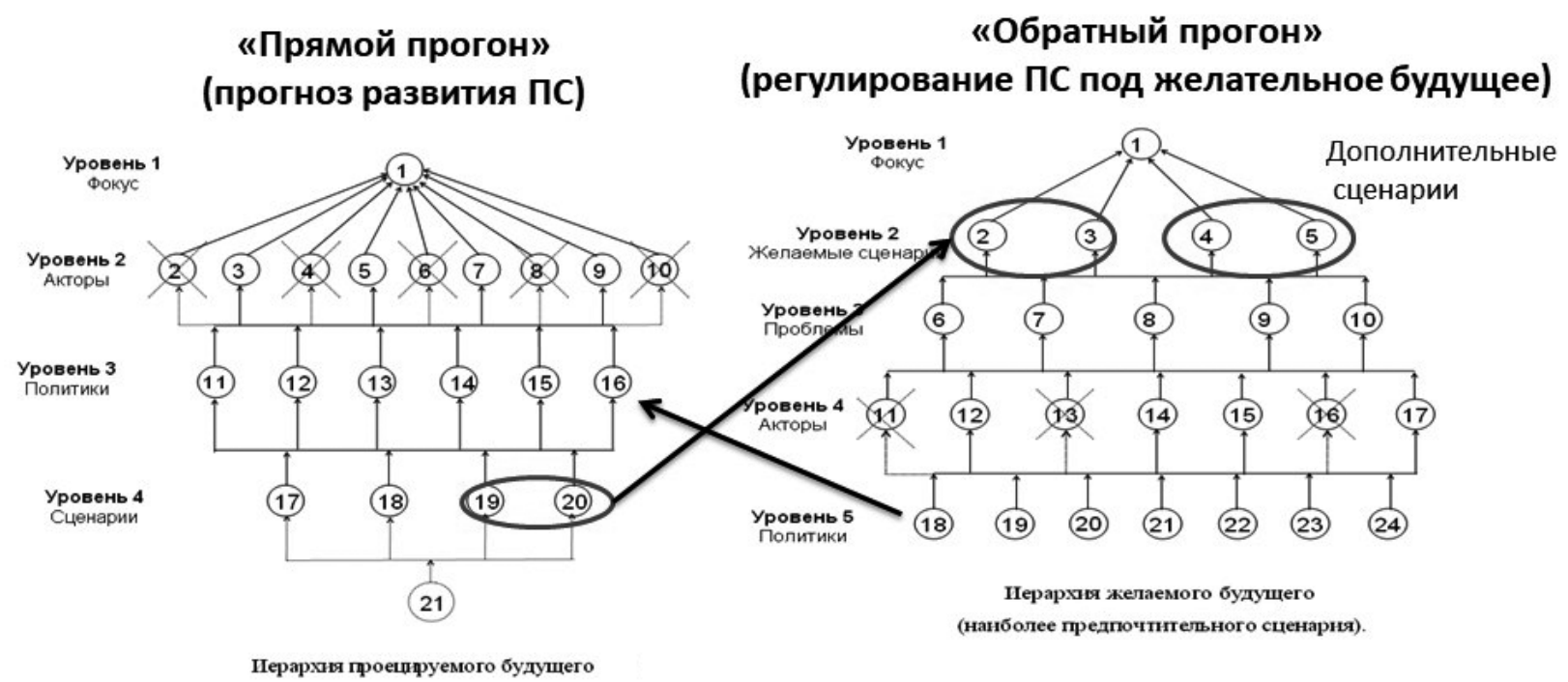

Рис. 3. Управление/стратегирование проблемными ситуациями в технопакетах 
управления командами. Кроме аналитических методов, ГСМ включает в себя (на этапе формирования/диагностики команды) батарею психологических тестов (MBTI, TSI структура интеллекта, невербальные тесты Торренса и др.), характеризующих ведущие индивидуально-типологические особенности (ВИТО) [12] как отдельных участников команд, так и команд в целом (например, модифицированный тест самовосприятия Р. Белбина, позволяющий оценить внутрикомандный уровень ролевого восприятия участниками друг друга), технологии метасценирования со сценарными пространствами различной сложности (S0, S1, S2, S3) [13], а также классические методы стратегического анализа PESTE, MIEP, STEPLE, SWOT и др.

Выбор конкретной «траектории» использования методов определяется исходя из оценки уровня неравновесности системысреды (К-уровня) и комплекса поставленных в исследовании задач [19]. Как и другие социальные практики, технология «технопакетов» тесно привязана к К-уровню, характеризующему конкретную проблемную ситуацию ПС (развитие технологических сред и т.д.) [10], ориентируясь на общие принципы креативного менеджмента: чем ближе к «кромке» хаоса, тем больше внимания уделяется поиску новых возможностей, чем дальше - тем больше внимания решению существующих проблем [18].

Управляющим субпакетом (гуманитарной технологией) ТП1 «управление командной работой» является информационно-аналитический субпакет «интегральная система моделей управления ТП», предназначенный для системного моделирования и управления технопакетом в целом. Такая система моделей управления ТП приведена на рис. 4, где opt $\mathrm{A}_{\mathrm{j}}^{\mathrm{i}}$ - оптимальная выходная характеристика на і-м этапе процесса системного управления командной работой, используемая как входной параметр на смежном (j + 1)-м этапе, например, наиболее привлекательный вид деятельности для организации при работе командами (управленческий консалтинг, сопровождение проектов, диагностика команды, развитие метакомпетенций команды и т.д.) используется как входной параметр для выбора оптимальных форм (ролевых, организационно-деятельностных игр, хирам, хакатонов, знаниевых реакторов и т.д.) и форматов организации мышления и поведения (мозговой штурм, синектика, шесть шляп Э. де Боно, системно-креативное мышление, ТРИЗ и т.д.) командной работы.

Синтез знаний в такой системе моделей/ субпакете проводится с помощью использования выходных характеристик, полученных на одном этапе управления отдельными субпакетами и технопакетом в целом во входные параметры моделей, используемых на других этапах, например, выбор наиболее привлекательных направлений командной работы влияет на выбор форм и форматов проектной работы команд, которые, в свою очередь, влияют на выбор методов управленческого проектирования и эффективность командной работы. По завершении одного цикла управления технопакетом процесс повторяется по схеме адаптации (см. рис. 3) до получения необходимого результата (достижения желаемого заказчиком проекта будущего).

Уровни управления технопакетом

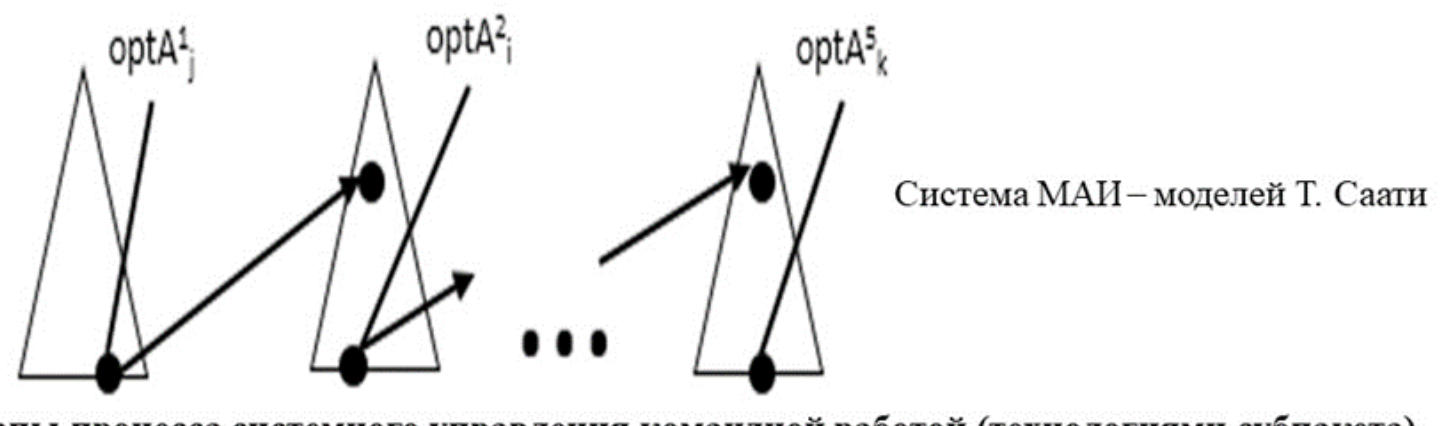

Этапы процесса системного управления командной работой (технологиями субпакета)

Рис. 4. Интегральная система моделей ТП «системное управление проектной командой» 
Заключение. В заключение можно сделать несколько выводов.

1. В условиях посттехногенной цивилизации (В. Лепский) и концепции соционавигации, при переходе от классического целевого к постнеклассическому атрибутивному проектированию и управлению особое значение приобретают технологии социального управления, основанные на модифицированной концепции «технопакетов» С. Переслегина.

2. Введение в концепцию «технопакетов» новых понятий «оптимизирующая» и «развивающая» технологии позволяет расширить и дифференцировать («тюнинг») инструментарий управления проектной командной работой, предоставляя дополнительные возможности управления системой/сетью технопакетов, создавая эффект синергии.

3. Развитие понятия «базовая» технология позволяет технологизировать трансформацию объекта технопакетов, что, в свою очередь, приводит к эволюционированию самого технопакета.

4. Предлагаемое развитие концепции технопакетов включает в себя различные взаимодействующие типы моделирования: «мягкие» вычисления, когнитивное моделирование и технологии искусственного интеллекта;

5. Синергетический эффект может быть достигнут не только за счет управления всеми этапами командной работой, но и за счет управления сетью технопакетов с использованием технологий системной аналитики и системно-креативного мышления.

\section{Литература}

1. Авдеева 3.К., Коврига С.В., Макарен-

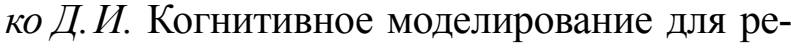
шения задач управления слабоструктурированными система (ситуациями) // Управление большими системами: сборник трудов. 2006. 一 №16. - С. 26-39.

2. Гроф С. Области человеческого бессознательного. - М.: Институт трансперсональной психологии, 1994. - С. 280.

3. Зарецкий B. K. Если ситуация кажется неразрешимой. - М.: Форум, 2019.

4. Кудрин Б. Н. Исследования технологических и технических систем как сообществ изделий-техноценозов. Системные исследования. - М.: 1982.
5. Лепский В.Е. Системные основания для перехода от техногенной цивилизации к социогуманитарной цивилизации. Проблемы цивилизационного развития, (1). 2019. - C. 33-48.

6. Локтионов М. В. Критика применения критической теории и критический системный подход в современных концепциях развития общества // Философская мысль. 2014. 一 №11. - С. 86-106.

7. Малинеикий Г.Г. Синергетика: Будущее мира и России. - М.: Либроком, 2008.

8. Михеев В.А., Федотова М.А., Шевьрев $A$. $B$. Рабочая команда как сетевая структура, индуцирующая единое креативное поле. Экономические стратегии, (5). — 2013. C. 64-67.

9. Перес $K$. Технологические революции и финансовой капитал. Динамика пузырей и периодов процветания. - М.: Дело, 2013.

10. Переслегин С.Б. Дикие карты будущего, форс-мажор для человечества [Электронный ресурс]. - М.: Алгоритм, 2015. C.407. - Режим доступа: https://www.litmir. $\mathrm{me} / \mathrm{br} / ? \mathrm{~b}=582662 \& \mathrm{p}=1$.

11. Синюк В.Г., Шевырев А. В. Использование информационно-аналитических технологий при принятии управленческих решений: учебное пособие. - М.: «Экзамен», 2003. - C. 157.

12. Собчик Л.Н. СМИЛ (ММРІ). Стандартизированный многофакторный метод исследования личности. - М.: Речь, 2009.

13. Сценарный стратегический прогноз. Пермский край, Россия и мир - 2030. - М.: ИНЭС РАН, 2016.

14. Уилбер К. Око духа: интегральное видение для слегка свихнувшегося мира. - М.: «Изд-во АСТ», 2002. - С. 476.

15. Федотова М.А. Постнеклассическое стратегирование проблемных ситуаций в концепции соционавигации: переход от целевого управления к атрибутивному конструированию. Экономические стратегии, 21 (8(166)). - 2019. - С. 94-101.

16. Федотова М.A. Системное управление командной работой: эволюция представлений и перспектива развития. Научный результат. Социология и управление, 4 (4). 2018. - C. 137-151.

17. Шевырев А.В. Технология творческого решения проблем (эвристический 
подход). - Белгород: Крестьянское дело, 1995. - Т. 2.

18. Шевырев А. Креативный менеджмент: синергетический подход. - Белгород: ЛитКараВан, 2007.

19. Шевырев А. В., Михеев В. А., Шаламова Н.Г., Федотова М.А. Системная аналитика в управлении. Введение в научно-исследовательскую программу (под общей редакцией Шевырева А.В.). - Белгород: ЛитКараВан, 2016. - C. 384.

20. Fedotova M., Khromova S., Argunovsky D., Polushin P. Hybrid Systems of Soft Computing Technologies in Designing Team Decision for Supply Chain Management Systems of Organizations. International Journal of Supply Chain Management. - Vol. 9. - №4, August 2020.

21. Konstantinov I., Fedotova M., Yin Bin. Modeling of training program development (determination of key metacompetencies, forms and formats) for international educational business project management: practical research results. International Journal of Supply Chain Management (IJSCM). — №5. - 2020.

22. Tart C.T. Consciousness, altered states, and worlds of experience. The Journal of Transpersonal Psychology, 18 (2). — 1986. P. 159-170.

\section{References}

1. Avdeeva Z.K., Kovriga S.V., Makarenko D.I. Kognitivnoe modelirovanie dlja reshenija zadach upravlenija slabostrukturirovannymi sistema (situacijami) [Cognitive modeling to solve management tasks semi structured system (situations)] // Upravlenie bol'shimi sistemami: sbornik trudov [Managing large systems: collection of papers]. 2006. - №16. - P. 26-39.

2. Grof S. Oblasti chelovecheskogo bessoznatel'nogo [Human unconscious]. - Moscow: Institut transpersonal'noj psihologii, 1994. P. 280 .

3. Zareckij V.K. Esli situacija kazhetsja nerazreshimoj [If the situation seems unsolvable]. - Moscow: Forum, 2019.

4. Kudrin B.N. Issledovanija tehnologicheskih i tehnicheskih sistem kak soobshhestv izdelij-tehnocenozov. Sistemnye issledovanija [Research technology and technical systems as communities products-technocenosis. System research]. - Moscow: 1982.

5. Lepskij V.E. Sistemnye osnovanija dlja perehoda ot tehnogennoj civilizacii $\mathrm{k}$ sociogumanitarnoj civilizacii. Problemy civilizacionnogo razvitija, (1) [System bases for transition from technogenic civilization to socio-humanitarian civilization. Problems of civilizational development, (1)]. - 2019. - Pp. 33-48.

6. Loktionov M. V. Kritika primenenija kriticheskoj teorii i kriticheskij sistemnyj podhod $\mathrm{v}$ sovremennyh koncepcijah razvitija obshhestva [Critique of the application of critical theory and critical system approach in modern concepts of society development] // Filosofskaja mysl'. 2014. — №11. - Pp. 86-106.

7. Malineckij G. G. Sinergetika: Budushhee mira i Rossii [Synergetics: the future of the world and Russia]. - Moscow: Librokom, 2008.

8. Miheev V.A., Fedotova M.A., Shevyrev A. V. Rabochaja komanda kak setevaja struktura, inducirujushhaja edinoe kreativnoe pole. Jekonomicheskie strategii, (5) [Working team as a network structure that induces a single creative field. Economic strategies, (5)]. — 2013. Pp. 64-67.

9. Peres $K$. Tehnologicheskie revoljucii i finansovoj kapital. Dinamika puzyrej i periodov procvetanija [Technological revolutions and financial capital. The dynamics of bubbles and periods of prosperity]. - Moscow: Delo, 2013.

10. Pereslegin S.B. Dikie karty budushhego, fors-mazhor dlja chelovechestva [Wild cards of the future, force majeure for humanity] [Jelektronnyj resurs]. - Moscow: Algoritm, 2015. - P. 407. — URL: https://www.litmir.me/ $\mathrm{br} / ? \mathrm{~b}=582662 \& \mathrm{p}=1$.

11. Sinjuk V.G., Shevyrev A.V. Ispol'zovanie informacionno-analiticheskih tehnologij pri prinjatii upravlencheskih reshenij: uchebnoe posobie [The use of information and analytical technologies in managerial decision making: a tutorial]. Moscow: «Jekzamen», 2003. - P. 157.

12. Sobchik L.N. SMIL (MMPI). Standartizirovannyj mnogofaktornyj metod issledovanija lichnosti [SMIL (MMPI). Standardized multifactor method of personality research]. - Moscow: Rech', 2009.

13. Scenarnyj strategicheskij prognoz. Permskij kraj, Rossija i mir - 2030 [Scenario strategic forecast. Perm region, Russia and the world - 2030]. - Moscow: INJeS RAN, 2016. 
14. Uilber K. Oko duha: integral'noe videnie dlja slegka svihnuvshegosja mira [Eye of spirit: integral vision for a slightly crazy world]. Moscow: «Izd-vo AST», 2002. - P. 476.

15. Fedotova M.A. Postneklassicheskoe strategirovanie problemnyh situacij v koncepcii socionavigacii: perehod ot celevogo upravlenija $\mathrm{k}$ atributivnomu konstruirovaniju [Post-nonclassical strategizing of problem situations in the concept of socionavigation: transition from target management to attribute design]. Jekonomicheskie strategii, 21 (8 (166)). - 2019. Pp. 94-101.

16. Fedotova M.A. Sistemnoe upravlenie komandnoj rabotoj: jevoljucija predstavlenij i perspektiva razvitija. Nauchnyj rezul'tat. Sociologija i upravlenie, 4 (4) [System management of team work: evolution of ideas and development prospects. Scientific result. Sociology and management, 4 (4)]. — 2018. - Pp. 137-151.

17. Shevyrev A.V. Tehnologija tvorcheskogo reshenija problem (jevristicheskij podhod) [Technology of creative problem solving (heuristic approach)]. — Belgorod: Krest'janskoe delo, 1995. - Vol. 2.

18. Shevyrev A. Kreativnyj menedzhment: sinergeticheskij podhod [Creative management: a synergetic approach]. — Belgorod: LitKaraVan, 2007.

19. ShevyrevA.V., Miheev V.A., Shalamova N.G., Fedotova M.A. Sistemnaja analitika v upravlenii. Vvedenie v nauchno-issledovatel'skuju programmu [System Analytics in management. Introduction to the research program] In Shevyrev A.V. (eds.). — Belgorod: LitKaraVan, 2016. - P. 384.

20. Fedotova M., Khromova S., Argunovsky D., Polushin P. Hybrid Systems of Soft Computing Technologies in Designing Team Decision for Supply Chain Management Systems of Organizations. International Journal of Supply Chain Management. - Vol. 9. - №4, August 2020.

21. Konstantinov I., Fedotova M., Yin Bin. Modeling of training program development (determination of key metacompetencies, forms and formats) for international educational business project management: practical research results. International Journal of Supply Chain Management (IJSCM). — №5. - 2020.

22. Tart C.T. Consciousness, altered states, and worlds of experience. The Journal of Transpersonal Psychology, 18 (2). - 1986. P. 159-170.

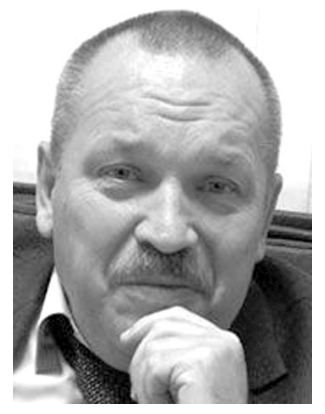

Бабинцев Валентин Павлович - доктор философских наук, профессор, профессор кафедры социальных технологий Белгородского государственного национального исследовательского университета.

Babintsev Valentin Pavlovich - Doctor of Philosophical Sciences, Professor, Professor of the Department of Social technologies, Federal State Autonomous Educational Institution of Higher Education «Belgorod State University».

308015, г. Белгород, ул. Победы, 85

85 Pobedy st., 308015, Belgorod, Russia

E-mail:babintsev@bsu.edu.ru 

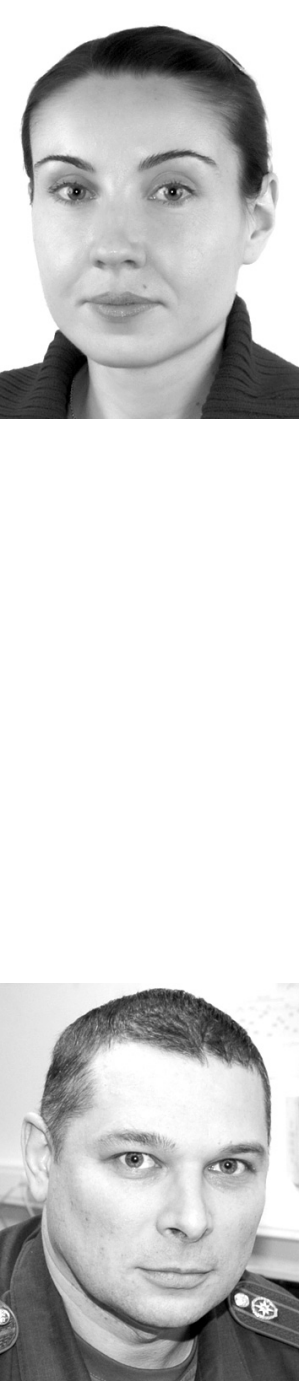

Федотова Марина Александровна - кандидат экономических наук, доцент кафедры «Управление персоналом» Московского авиационного института (национального исследовательского университета).

Fedotova Marina Alexandrovna - Candidate of Economic Sciences, Associate Professor of Department «Human resource management», Moscow Aviation Institute (National Research University).

125993 , г. Москва, Волоколамское шоссе, 4 4 Volokolamsk highway, 125993, Moscow, Russia E-mail: fedotova-ma@yandex.ru

Полушин Петр Владимирович - заместитель начальника учебного отдела учебно-методического центра Академии Государственной противопожарной службы МЧС России.

Polushin Petr Vladimirovich - Deputy Head of the Training Department of the Training Center, Academy of the State fire service of the EMERCOM of Russia.

129366, г. Москва, ул. Бориса Галушкина, 4

4 Boris Galushkin st., 129366, Moscow, Russia

E-mail: petr-poluchin@rambler.ru 